\title{
Management of rheumatoid arthritis in People's Republic of China - focus on tocilizumab and patient considerations
}

This article was published in the following Dove Press journal:

International Journal of General Medicine

12 May 2015

Number of times this article has been viewed

\author{
Geng Wang' \\ Rong $\mathrm{Mu}^{2}$ \\ Huji Xu' \\ 'Department of Rheumatology and \\ Immunology, Changzheng Hospital, \\ The Second Military Medical \\ University, Shanghai, ${ }^{2}$ Department \\ of Rheumatology and Immunology, \\ Peking University People's Hospital, \\ Beijing, People's Republic of China
}

Correspondence: Huji Xu Department of Rheumatology and Immunology, Changzheng Hospital, The Second Military Medical University, No 415 Fengyang Road, Shanghai 200003, People's Republic of China

Tel +862181885513

Fax +86 21 635I 984I

Email xuhuji@smmu.edu.cn
Abstract: The prevalence of rheumatoid arthritis (RA) is $0.19 \%-0.41 \%$ in Chinese population. RA exerts profound influence on health-related quality of life (HRQoL), which imposed huge burdens on patients physically, mentally, and economically. As a developing country, People's Republic of China faces enormous challenges in management of RA. Conventional-synthesized disease-modifying antirheumatic drugs (csDMARDs) remain the most selective therapeutic options for RA in People's Republic of China owing to their affordable price and fair efficacy as well as tolerability. Unfortunately, there are substantial RA patients who are poor responders to csDMARDs, even to subsequently combined therapy with tumor necrosis factor antagonist (anti-TNF). Tocilizumab (TCZ) has been approved as a subsequent-line biological agent in patients with moderate-to-severe RA worldwide including People's Republic of China. TCZ is the first biological agent approved for the treatment of RA inhibiting interlukin-6 (IL-6) by blocking both membrane-bound and soluble IL-6 receptors. Open-label studies in real-life practice and strictly controlled clinical trials demonstrated its high efficacy and safety profile in treatment of patients with RA who have inadequate responses to csDMARDs and anti-TNF. HRQoL of RA patients was improved in various measurements. TCZ was associated with 1.2 times the risk of adverse events, such as infections, dyslipidemia, and hepatic transaminases elevation, compared with pooled placebo. A relatively long half-life allowing for monthly intravenous administration and a newly developed subcutaneous injection make TCZ more acceptable. However, data are not enough so far comparing TCZ to anti-TNF. Lack of evidence in Chinese patients and high cost of TCZ limit its prescription in People's Republic of China being a developing country. Further clinical trials and post-marketing surveillance may offer a comprehensive assessment of patient satisfaction and acceptability, which may help us define the optimal role for TCZ in therapeutic strategy.

Keywords: rheumatoid arthritis, IL-6, tocilizumab, People's Republic of China, health-related quality of life

\section{Management of Chinese patients with rheumatoid arthritis in general}

Rheumatoid arthritis (RA) is a chronic multisystem inflammatory autoimmune disease. In addition to synovitis which involves peripheral joints symmetrically, there are diverse ranges of systemic manifestations. The disorder is most typically prevalent in the female and elderly. The progressive multi-joint damage and other autoimmune symptoms substantially cause increased disability. Unfortunately, limited solutions were available for this old foe for decades. A huge step has been taken in 1980 since methotrexate (MTX) is being widely used as first-line therapeutic agent in early stage of patients with RA. It is followed by the appearance of first biologic agent at the 
beginning of this century - tumor necrosis factor antagonist (anti-TNF). ${ }^{1}$

The newly reported epidemiological data revealed that the prevalence of RA in total Chinese population was $0.28 \%$ ( $95 \%$ confidence interval $0.19 \%, 0.41 \%$ ), as the ratio of female:male is nearly $6: 1(0.46 \%$ versus $0.08 \%))^{2}$ In People's Republic of China, conventional-synthesized diseasemodifying antirheumatic drugs (csDMARDs) like MTX, sulfasalazine, hydroxychloroquine, and leflunomideare were most widely prescribed due to their low costs and fair efficacy. However, biological agents that specifically inhibit activity of certain proinflammatory cytokines are usually administered to patients whose arthritis cannot be well managed or tolerate adverse effects with csDMARDs. ${ }^{3}$ Therapeutic options for RA increased rapidly in the last decade. Anti-TNF $\alpha$ was the first and the most selected biologic used in People's Republic of China, followed by tocilizumab (TCZ). Infectious diseases especially hepatitis B and tuberculosis (TB) restrict the prescription of biologics. High cost is another obstacle for usage of biologics in People's Republic of China taking its economic status and health care system into considerations. Less than $10 \%$ of RA patients in People's Republic of China received anti-TNF $\alpha$ therapy. ${ }^{4}$ High quality of life, low disability rate, treat to target, and long-term remission induced by safe, tolerable, and relatively short-term treatment are the final goals for RA management. ${ }^{1}$ The objective of this review is mainly to summarize the up-to-date information and perspectives on TCZ and the current status of RA management in People's Republic of China.

\section{Introduction to interleukin-6 in RA}

Interleukin-6 (IL-6) is a pleiotropic proinflammatory cytokine with multiple biological activities. IL-6 exerts its biological functions through both the alpha chain of IL-6 receptor (IL-6R $\alpha$ ) and glycoprotein 130 (gp130). IL-6 initiates cellular activation through two signaling pathways by two different types of IL-6R $\alpha$, a membrane-bound receptor (mIL-6R) and a soluble one (sIL-6R). Once IL-6 binds to mIL-6R, a hexameric complex of high affinity composed of two molecules each of IL-6, IL-6R, and gp130 is formed. Known as classical IL-6 signaling pathway, mIL-6R only appears on surface of certain types of cells like hepatocytes, neutrophils, and macrophages, whereas IL-6 can also bind to the circulating sIL-6R shaping into a complex with gp130 which activates the IL-6 trans-signaling as gp130 is more universal on cells. ${ }^{5}$

In human, IL-6 actively involves in the course of fighting against pathogens, acute stress, and even prolonged inflammation by targeting on B cells, T cells, hemocytoblasts, fibroblasts, and hepatocytes, just to name a few. ${ }^{6}$ In acute inflammatory diseases, macrophages and monocytes produce the majority of IL-6. In this process, toll-like receptors are activated via binding to distinct pathogen-associated molecular patterns through a myeloid differentiation factor 88 (MyD88)-dependent pathway. T cells act more like a primary generator of IL-6 in chronic inflammation. ${ }^{7}$ Then, through either pathway, IL-6 participates in acute and chronic immune responses, hematopoiesis, and bone metabolism by inducing cell differentiation and gene expression. ${ }^{8}$ The overproduced IL-6 promotes genesis of acute phase proteins such as $\mathrm{C}$ reactive protein (CRP), fibrinogen, hepcidin, and amyloid A, while it reduces synthesis of albumin and cytochrome $\mathrm{P} 450$. The increase and decrease in the proteins mentioned above can be monitored not only in acute but in chronic inflammatory diseases as well. ${ }^{7}$

Additionally, IL-6 induces immunoglobulin synthesis in activated B cells, cytotoxic T cells, and IL-17-producing $\mathrm{T}$ helper cells (Th17). In development of medullary cells, IL-6 stimulates generation of platelets from megakaryocytes and activates hematopoietic stem cells. Moreover, acting on synovial fibroblast cells, IL-6 induces the production of vascular endothelial growth factor (VEGF) and NF- $\kappa B$ ligand (RANKL), which leads to VEGF-dependent angiogenesis and differentiation of osteoclasts, ${ }^{9}$ respectively. Furthermore, IL-6 may also activate the dermal fibroblastsinduced collagen production leading to autoimmune skin diseases. $^{10}$

Thus, with the biological functions as described above, deregulation of IL- 6 definitely leads to a variety of human diseases including RA. ${ }^{5}$ IL-6's elevation both in serum and synovial fluids in patients with RA is responsible for pathogenesis in patients with RA, such as T cells differentiation, osteoclast activation, synovial fibroblasts proliferation, and chronic synovial inflammation. ${ }^{11}$

\section{Pharmacokinetics of TCZ}

TCZ, a novel treatment intervention for RA, is designed as a recombinant humanized monoclonal antibody inhibiting IL- 6 by the blockage of anti-IL-6R specifically. The complementarity-determining regions of a murine monoclonal antibody to human IL-6R were in fusion with human immunoglobin subclass G1. ${ }^{12}$ By blocking the binding to both mIL-6R and sIL-6R, TCZ retards IL-6's initiation of either classic or signaling pathways. ${ }^{11}$ Therefore, it blocks the pro-inflammatory effects of IL-6. TCZ is approved at a dose of $8 \mathrm{mg} / \mathrm{kg}$ per 4 weeks (q4w) for treating RA patients 
in Japan, US, most of the European countries, and People's Republic of China. ${ }^{13}$

The studies on pharmacokinetics of TCZ began with a multiple-dose open-label trial ( $2 \mathrm{mg} / \mathrm{kg}, 4 \mathrm{mg} / \mathrm{kg}$, or $8 \mathrm{mg} / \mathrm{kg}$ ). The grouped $15 \mathrm{RA}$ patients received TCZ intravenously (TCZ-IV) biweekly, and the efficacy, safety, and pharmacokinetics of TCZ were assessed at week 6 . The study exhibited a nonlinear increase in serum TCZ concentrations with ascending of dosage. TCZ was detectable in $70 \%$ of the patients from $2 \mathrm{mg} / \mathrm{kg}$ and $4 \mathrm{mg} / \mathrm{kg}$ groups and all recipients in $8 \mathrm{mg} / \mathrm{kg}$ group at week 6 . After the third dose in the $8 \mathrm{mg} / \mathrm{kg}$ group, the half-time, prolonged with multiple infusion and increased dosage, reached 241.8 \pm 71.4 hours. Regarding the three groups as a whole, at week 6, 60\% of patients achieved American College of Rheumatology (ACR) 20. At week 24, 87.7\% of patients achieved ACR20, and $33.3 \%$ achieved ACR50. ${ }^{14}$ Better-controlled trials then indicate that the total clearance of TCZ appears to be biphasic with different TCZ concentrations. Duel effects of linear and nonlinear clearance result in its concentration-dependent clearance macroscopically. Moreover, TCZ has a long halflife allowing for administration every 4 weeks. ${ }^{15}$

With the development of subcutaneous TCZ injection (TCZ-SC), ${ }^{16}$ pharmacokinetics of TCZ-SC was investigated in an open-label study (MATSURI study). ${ }^{17}$ The noncompartmental analysis determined the initial dosage of $162 \mathrm{mg}$. The area under the concentration curve was $96.7 \pm 53.7 \mathrm{mg}$ day/ $\mathrm{mL}$, and the time to maximal concentration $\left(t_{\max }\right)$ ranged from
2.0 days to 7.2 days. The half-life was $1.6 \pm 0.24$ days after the initial $162 \mathrm{mg}$ given subcutaneously. In Phase III study comparing TCZ-SC to TCZ-IV as monotherapy, serum trough TCZ concentrations of TCZ-SC (162 mg biweekly) were as adequate as TCZ-IV ( $8 \mathrm{mg} / \mathrm{kg}$ every 4 weeks $)$ and over time in duration of 24 weeks. ${ }^{18}$

\section{Efficacy studies on TCZ}

In complementary to the satisfactory outcomes of open-label study, the efficacy was convinced by following Phase III clinical trials of TCZ. To date, there are approximately 160 registered studies worldwide on clinical trials website (http:// www.clinicaltrials.gov) providing efficacy data on patients with RA who received TCZ monotherapy or combined with csDMARDs. As of August 2014, among all the trials that used TCZ as study agent, eight included People's Republic of China as one of the study locations, while only five listed as completed with results or publications. ${ }^{19-23}$ Details of the sample size, protocols, national clinical trial registry numbers, and results of the five completed Phase III studies are displayed in Table 1.

A Cochrane database systematic review included eight qualified Phase III trials with 3,334 participants (2,233 treated with TCZ; 1,101 control). In most randomized controlled trials (RCTs), TCZ was combined with previous MTX or other csDMARDs treatment. In a nutshell, patients treated with TCZ were four times more likely than patients in control group to achieve ACR50 (40\% versus 10\%) and eleven times

Table I Registered clinical trials that use tocilizumab for treating RA in Chinese location

\begin{tabular}{|c|c|c|c|c|}
\hline Trials & $\begin{array}{l}\text { Patients } \\
\text { (n) }\end{array}$ & Protocols & Results & $\begin{array}{l}\text { NCT } \\
\text { number }\end{array}$ \\
\hline $\begin{array}{l}\text { Phase III } \\
\text { LITHE } \\
\text { DBRPCT }\end{array}$ & 1,196 & $\begin{array}{l}\text { Arm I: TCZ } 4 \mathrm{mg} / \mathrm{kg} q 4 \mathrm{w}(\mathrm{IV})+\mathrm{MTX} \\
\text { Arm 2: TCZ } 8 \mathrm{mg} / \mathrm{kg} q 4 \mathrm{w}(\mathrm{IV})+\mathrm{MTX} \\
\text { Arm 3: placebo } \mathrm{q} 4 \mathrm{w}(\mathrm{IV})+\mathrm{MTX}\end{array}$ & $\begin{array}{l}\text { At week 104, mean change from baseline in GmTSS was } \\
\text { significantly lower in Arm I }(0.58 ; P=0.0025) \text { or Arm } 2 \\
(0.37 ; P<0.000 \text { I) than for patients in Arm } 3(1.96)\end{array}$ & NCT00I06535 \\
\hline $\begin{array}{l}\text { Phase III } \\
\text { DBRPCT }\end{array}$ & $\mathrm{I}, 157$ & $\begin{array}{l}\text { Arm I: TCZ } 4 \mathrm{mg} / \mathrm{kg} q 4 \mathrm{w}(\mathrm{IV})+\mathrm{MTX} \\
\text { Arm 2: TCZ } 8 \mathrm{mg} / \mathrm{kg} q 4 \mathrm{w}(\mathrm{IV})+\mathrm{MTX} \\
\text { Arm 3: TCZ } 8 \mathrm{mg} / \mathrm{kg} q 4 \mathrm{w}(\mathrm{IV})+\text { placebo } \\
\text { Arm 4: placebo } \mathrm{q} 4 \mathrm{w}(\mathrm{IV})+\mathrm{MTX}\end{array}$ & $\begin{array}{l}\text { At week } 24 \text {, DAS } 28 \text { remission was achieved in } 31.9 \% \text {, } \\
44.8 \% \text {, and } 38.7 \% \text { of patients in Arm I, } 2 \text {, and } 3 \text {, } \\
\text { respectively, compared with } 15 \%(P<0.0001) \text { of patients } \\
\text { treated with placebo in Arm } 4\end{array}$ & NCTOI007435 \\
\hline $\begin{array}{l}\text { Phase III } \\
\text { TOWARD } \\
\text { DBRPCT }\end{array}$ & $\mathrm{I}, 220$ & $\begin{array}{l}\text { Treatment: TCZ } 8 \text { mg/kg q4w (IV) + csDMARDs } \\
\text { Control: placebo q4w (IV) + csDMARDs }\end{array}$ & $\begin{array}{l}\text { At week } 24 \text {, the proportion of patients who met ACR20 } \\
\text { was significantly greater in the TCZ plus csDMARD group } \\
\text { than MTX alone }(61 \% \text { versus } 25 \% ; P<0.000 \text { I) }\end{array}$ & NCT00I06574 \\
\hline $\begin{array}{l}\text { Phase III } \\
\text { AMBITION } \\
\text { DBRPCT }\end{array}$ & 673 & $\begin{array}{l}\text { Treatment: TCZ } 8 \text { mg/kg q4w (IV) + placebo } \\
\text { Control: placebo q4w (IV) + MTX }\end{array}$ & $\begin{array}{l}\text { At week } 24, \mathrm{TCZ} \text { was associated with a significantly } \\
\text { higher ACR20 response than MTX }(69.9 \% \text { versus } 52.5 \% \text {; } \\
P<0.00 \text { I }) \text {, and rate of DAS28 }<2.6(33.6 \% \text { versus } 12.1 \%)\end{array}$ & NCT00I09408 \\
\hline $\begin{array}{l}\text { Phase III } \\
\text { OPTION } \\
\text { DBRPCT }\end{array}$ & 623 & $\begin{array}{l}\text { Arm I: TCZ } 4 \text { mg/kg q4w (IV) + MTX } \\
\text { Arm 2: TCZ } 8 \text { mg/kg q4w (IV) + MTX } \\
\text { Arm 3: placebo q4w (IV) + MTX }\end{array}$ & $\begin{array}{l}\text { At week } 24 \text {, higher ACR20 response rates could be noticed } \\
\text { in patients receiving TCZ than placebo }(59 \% \text { in Arm } 2 \text { and } \\
48 \% \text { in Arm I versus } 26 \% \text { in Arm } 3 ; P<0.000 \text { I) }\end{array}$ & NCT00I06548 \\
\hline
\end{tabular}

Abbreviations: ACR, American College of Rheumatology; csDMARD, conventional-synthesized disease-modifying antirheumatic drug; DAS, disease activity score; DBRPCT, double-blind randomized placebo-controlled trial; GmTSS, Genant-modified Total Sharp Score; MTX, methotrexate; NCT, national clinical trial; q4w, every 4 weeks; RA, rheumatoid arthritis; TCZ, tocilizumab; IV, intravenous. 
more likely to achieve disease activity score (DAS) remission (30\% versus 3\%). ${ }^{24}$ In addition, TCZ also attenuated radiographic progression in RA. The SAMURAI (the study of active controlled monotherapy used for rheumatoid arthritis, an IL-6 inhibitor) ${ }^{25}$ and LITHE (tocilizumab safety and the prevention of structural joint damage $)^{20}$ studies provided data that revealed the superior efficacy of TCZ retarding radiographic disease progression to placebo, although further discussion and evidences are needed. Moreover, health-related quality of life (HRQoL) in TCZ-treated patients exceeded those with placebo significantly. ${ }^{24}$

Based on data of clinical trials, anti-IL-6RAb seems to have equivalent efficacy to the other biologics for the treatment of RA. ${ }^{26}$ Indirect comparisons showed that, though with different enrolled populations and placebo response rates, the efficacy of TCZ seems to be equivalent to other approved biologics for treatment of RA including etanercept, infliximab, adalimumab, golimumab, rituximab, and abatacept, and better than anakinra. ${ }^{24}$ The newly reported ADACTA ${ }^{27}$ as the first head-to-head clinical trial provided more convincing data of TCZ monotherapy versus adalimumab monotherapy. The direct comparison revealed the TCZ's superiority of 28-joint disease activity score (DAS28) reduction from baseline in treating RA patients who were poor responders to MTX.

Among non-anti-TNF agents, only TCZ-IV ( $8 \mathrm{mg} / \mathrm{kg} \mathrm{q4w})$ as a monotherapy has been repeatedly demonstrated to be superior to MTX or other csDMARDs. Thus, it was placed in the same level as other biologics. However, TCZ as monotherapy or part of the initial regimen was not advocated in European League Against Rheumatism 2013 updates. ${ }^{28}$

The newly developed subcutaneous injection route makes it an ideal alternative for patients and physicians. The efficacy and safety of TCZ-SC as monotherapy in treatment of RA were investigated in a double-blind, double-dummy, and parallel-group comparative Phase III trial. ${ }^{18}$ TCZ-SC monotherapy (162 mg/2 weeks) presented similar efficacy and safety to TCZ-IV ( $8 \mathrm{mg} / \mathrm{kg} / 4$ weeks). The confirmation of equivalency of TCZ-SC to TCZ-IV provides additional treatment alternative for patients with RA. Nonetheless, further investigations are needed, and TCZ-SC is not available in People's Republic of China currently.

In People's Republic of China specifically, the evaluation of combined therapy of TCZ and csDMARDs in Chinese patients with RA was lately reported in a multicenter, randomized, double-blinded, placebo-controlled trial (MCRDBPCT). It demonstrated the efficacy and safety of TCZ plus csDMARDs in treating active RA patients. ${ }^{29}$ Randomized 208 patients who have unsatisfied response to csDMARDs
(TCZ:placebo $=2: 1$ ) received a single dose of TCZ $8 \mathrm{mg} / \mathrm{kg}$ or placebo every 4 weeks intravenously (iv) along with stable dose of disease-modifying antirheumatic drugs (DMARDs). At week 24, improvement in disease activity was observed by response criteria of the ACR. The proportion of patients who met the efficacy endpoint ACR20, ACR50, and ACR70 in TCZ group was superior to those who received placebo: $69.8 \%$ versus $24.6 \%(P<0.05), 38.8 \%$ versus $10.1 \%(P<0.05)$, and $12.9 \%$ versus $2.9 \%(P<0.05)$, respectively. Remission of RA was scaled by ratio of achieving DAS $28 \leq 3.2$ (46.6\% versus $4.7 \%$ ) and DAS28 $<2.6(30.5 \%$ versus $3.1 \%)$, which appears much better in TCZ group than placebo group.

In summary, monotherapy of TCZ (AMBITION, the Actemra versus methotrexate double-blind investigative trial in monotherapy) $)^{22}$ or in combination with MTX is superior to MTX alone or placebo in disease activity remission in duration of at least 24 weeks with Chinese patients' participation.

\section{Safety and tolerability}

Safety of a novel therapeutic agent always has the priority in clinical practice. The safety of TCZ was first studied in an open-label trial with 15 patients with active RA. Grouped patients were administered iv with three different dosages ( $2 \mathrm{mg} / \mathrm{kg}, 4 \mathrm{mg} / \mathrm{kg}$, or $8 \mathrm{mg} / \mathrm{kg}$ ) of TCZ biweekly for 24 weeks. There was no dose-dependent increase in the frequency of adverse events (AEs) among the three dose groups. ${ }^{14}$

A systematic review of TCZ in treatment of RA reported that the probability of AEs in TCZ groups is $74 \%$ while $65 \%$ in pooled placebo patients. Neither serious AE (SAE) nor withdrawals due to AE were reported to be significantly different from placebo group. ${ }^{24}$ A Cochrane review compared the safety profile of TCZ to other biologics in treating RA (anti-TNF, anakinra, abatacept, rituximab). It showed no statistically significant difference in rates of SAE, serious infections, lymphoma, and congestive heart failure. ${ }^{30}$

Infections or infestations, as a TCZ-related AE, have been most frequently reported. ${ }^{23}$ Nasopharyngitis and upper respiratory tract infection take the majority of them. ${ }^{22}$ The most frequent AE in SAMURAI study was nasopharyngitis, ${ }^{25}$ while the case was dyspepsia and abdominal pain in OPTION (tocilizumab pivotal trial in methotrexate inadequate responders) trial. ${ }^{23}$ Dyslipidemia was seen in the TCZ-treated patients. Reversible elevations in total serum, high-density lipoprotein and low-density lipoprotein cholesterol, and triglyceride level occurred in many cases. ${ }^{31}$ Besides, transient or intermittent elevations of hepatic transaminases have been 
commonly reported in patients receiving TCZ in clinical trials. TCZ therapy does also alter hematological parameters. TCZ was associated with dose-dependent transient neutropenia and thrombocytopenia. ${ }^{15}$ In addition to common AEs, infusion reactions (reactions occurring within 24 hours after infusion), allergy, and hypersensitivity may occur with symptoms like skin eruption, fever, and headache. ${ }^{32}$ Cases of TB infections have been reported in clinical trials and post-marketing surveillance studies of TCZ. ${ }^{30}$ Although the safety concerns of TCZ in patients with active hepatitis infections are unclear, the screening process of TB and hepatitis prior to TCZ administration is a must, especially in People's Republic of China.

From the limited data of RCT in People's Republic of China, the MCRDBPCT mentioned above revealed that infection was the most common AE. Most of the AEs were mild to moderate which did not cause withdrawals. SAEs occurred in $0.7 \%$ and $5.9 \%$ of patients in the TCZ and control groups, respectively. The percentage of increases in serum level of alanine transaminase and aspartate transaminase in the TCZ group exceeded the placebo group (alanine transaminase, $12.9 \%$ versus $4.4 \%$; aspartate transaminase, $9.4 \%$ versus $4.4 \%$ ). Mild-to-moderate dyslipidemia was observed in the TCZ group but not correlated to increase in occurrence of cardiac events. ${ }^{33}$

Malignancy posed another question mark on TCZ and other biologics. The probability of malignancies occurrence in patients with RA undergoing treatment with biologics including TCZ was reviewed in a meta-analysis. Within included RCTs in duration of at least 24 weeks, the data of TCZ given to patients with RA compared with csDMARDs or with placebo did not suggest valid association with an increased risk of malignancy. ${ }^{34}$

Given the absence of valid data on human, TCZ is not recommended during pregnancy and lactation. The only support of its safety in fertility is from data on cynomolgus monkeys, which suggest no evidence of deleterious effect on the pregnancy or on fetal development. Although potential risk of abortion or fetal death was showed in animal test, the dosage of $10 \mathrm{mg} / \mathrm{kg} /$ day and $50 \mathrm{mg} / \mathrm{kg} /$ day in animal test is much higher than human dose of $8 \mathrm{mg} / \mathrm{kg} / \mathrm{month}$. In addition, TCZ is not recommended while breastfeeding; hence, no data on TCZ secretion in human breast milk or in animal milk are available. ${ }^{35}$

\section{Perspectives on patient's quality of life}

HRQoL indicates the effect of therapy and disease itself on well-being of patients. Patients with RA show notable decrease in HRQoL owing to associated manifestations including pain, disability in physical function, and fatigue. Based on data from the National Health and Wellness Survey 2009 of urban People's Republic of China (18.1\% of the total adult population in People's Republic of China), ${ }^{36}$ the prevalence of RA in People's Republic of China imposed substantial economical effect on HRQoL, as RA may correlate to lowering the workforce participation likelihood and enhancing absenteeism and presenteeism. Measured by the physical component summary (PCS) and the mental component summary (MCS) and 6-Dimension Short-Form Health Survey (SF-6D) utilities, the HRQoL was scaled in multiple dimensions generally, physically, socially, mentally, and emotionally. ${ }^{32}$ In terms of PCS, MCS, and utilities, the deficit impact of RA was $-2.3,-1.5$, and -0.025 , respectively. For general health and well-being, the odds ratio of the RA presence was $1.3 .^{36}$

Different HRQoL measurements have been employed in clinical trials of RA like the 36-item Short-Form Health Survey (SF-36) and the Heath Assessment Questionnaire (HAQ) ${ }^{37}$ Published in 1978, HAQ is still regarded as the most authoritative functional measurement of patients with arthritis, though it has been updated constantly over past several years due to its lengthiness and complexity. Multidimensional Health Assessment Questionnaire is the latest released version. ${ }^{38}$

For a valid and practical quantitative measurement of HRQoL, localization is necessary and pivotal. Chinese Multidimensional Health Assessment Questionnaire (MDHAQ-C) is well adapted to Chinese culture and status in quo. The clinical practicability and psychometric properties of MDHAQ-C have been evaluated in a clinical trial with 162 Chinese RA patients enrolled. With valid and reasonable categories, MDHAQ-C showed comprehensive capability in scaling functional status of patients from mild to severe. It also has relatively high correlation with DAS28 and Clinical Disease Activity Index. For both Chinese medical practitioners and RA patients, MDHAQ-C proved to be a reliable and informative measurement for HRQoL in demanding clinical settings. ${ }^{39}$

Several trials reported that significant benefits were noticed with TCZ in terms of improving HRQoL. ${ }^{15}$ The change of HAQ from baseline or achievement of HAQ-minimum clinically important differences (MCID) (reduce more than 0.22 ) was repeatedly showcased in different clinical trials of TCZ. ${ }^{40}$

Apparent improvements in HRQoL measures were associated with TCZ monotherapy or TCZ plus MTX or other csDMARDs in active RA patients from moderate to 
severe. In the OPTION trial, with mean disease duration of 7.5 years, 623 treatment-experienced active RA patients having inadequate responses to csDMARDs were randomized into three groups, TCZ (4 mg/ $\mathrm{kg}$ or $8 \mathrm{mg} / \mathrm{kg}$ iv) with MTX versus recipients taking MTX alone. At week 24, in both $4 \mathrm{mg} / \mathrm{kg}$ and $8 \mathrm{mg} / \mathrm{kg}$ groups, mean improvements were obviously significant. SF-36 scores exceeded MCID in both PCS $(P<0.0001)$ and MCS $(P<0.05) .{ }^{23}$ In LITHE study, enrolled 1,196 patients were divided into three arms. At week 104, significant changes from baseline in HAQ were observed in TCZ $4 \mathrm{mg} / \mathrm{kg}$ plus MTX and TCZ $8 \mathrm{mg} / \mathrm{kg}$ plus MTX comparing to patients in placebo group $(P<0.0001$ for both comparisons). ${ }^{41}$ Similarly, in the TOWARD (tocilizumab in combination with traditional DMARD therapy) trial, with average course of 9.8 years, 1,220 patients with active RA failed to have well response to csDMARDs received TCZ $8 \mathrm{mg} / \mathrm{kg}$ with csDMARDs or placebo with csDMARDs. TCZ plus csDMARDs therapy significantly meliorated the disease activity of recipients from baseline $(P<0.0001)$ and reached MCID in all SF-36 domains $(P<0.0001) .{ }^{21}$ In the RADIATE (research on Actemra determining efficacy after anti-TNF failures) trial, 489 patients with refractory RA with futile treatment with at least one anti-TNF and mean disease duration of $11.0-12.6$ years received TCZ ( $4 \mathrm{mg} / \mathrm{kg}$ or $8 \mathrm{mg} / \mathrm{kg}$ iv $\mathrm{q} 4 \mathrm{w})$ plus MTX or placebo plus MTX for 24 weeks. Greater than MCID reported in both $4 \mathrm{mg} / \mathrm{kg}$ or $8 \mathrm{mg} / \mathrm{kg} \mathrm{TCZ}$ groups were statistically significant in both Health Assessment Questionnaire-Disability Index (HAQ-DI) and SF-36 domain PCS scores (4 mg/kg: $P<0.005$ [HAQ-DI], $P<0.005$ [PCS]; $8 \mathrm{mg} / \mathrm{kg}: P<0.0001$ [HAQ-DI], $P<0.005$ [PCS] ). ${ }^{42} \mathrm{In}$ SATORI study, TCZ monotherapy was demonstrated to have beneficial impact on HRQoL. The clinical improvement from baseline in modified HAQ scores was significant $(P<0.01)$ over 24 weeks with TCZ $8 \mathrm{mg} / \mathrm{kg}$ versus MTX alone $(67 \%$ versus 34\%) ${ }^{43}$ In AMBITON trial, the superiority of TCZ versus MTX as monotherapy in ameliorating physical well-being was reflected by notable changes from baseline in HAQ-DI with an adjusted mean treatment difference of -0.2. ${ }^{22}$

TCZ, as a newly marketed biological agent in People's Republic of China, was only prescribed to moderate-tosevere RA patients who were refractory to csDMARDs and anti-TNF therapy. Although superior efficacy and less frequent infusions (monthly) make it an attractive option for patients, further clinical trials and post-marketing surveillance are demanded for a better assessment of patient satisfaction and acceptability.

High cost of medication imposed another burden on patients themselves due to no coverage of national health insurance. Moreover, the newly developed TCZ-SC may enhance the compliance of patients with RA. However, it is not currently approved in People's Republic of China.

\section{Conclusion and future perspectives}

Therapeutic management of RA should be individualized owing to a wide spectrum of patient preference and therapeutic traits, such as economic conditions, disease severity, underlying diseases, efficacy and safety, routes of administration, and facility requirements. Thanks to its affordable price and fair efficacy and tolerability, MTX is still considered as the initial choice and gold standard of DMARDs. However, csDMARDs, even anti-TNF, fail to manage quite a few patients who cannot achieve long-term remission of RA.

TCZ is the first biologic used for the treatment of RA targeting IL-6R. It presents an effective therapeutic alternative to those who were refractory to csDMARDs and anti-TNF. Although the efficacy and tolerability of TCZ as a subsequent biological agent were well established by several clinical trials in treatment of active RA, the comparative data are not enough comparing to anti-TNF. ${ }^{44}$ In addition, lack of postmarketing surveillance and high cost of using TCZ limit its popularization in People's Republic of China.

Future studies that help us define the optimal biologic or csDMARDs for each individual based on their characteristics and pharmacogenomics are needed. ${ }^{12}$ TCZ-associated abnormalities in lipid levels and transaminase were detected in many trials. New biological agents that target directly IL-6 but not its receptor are eagerly awaited. Development of this strategy may reduce these adverse effects. ${ }^{10}$

In a word, TCZ potentially offers a novel option inhibiting IL-6 in patients with RA. Studies worldwide have confirmed its efficacy in reducing disease activity and slowing radiographic destruction in RA. As a brand new biologic in People's Republic of China, TCZ currently plays a "supporting role" or acts as an "intern" in clinical scenarios of RA management. There are several efficacy and safety concerns with TCZ that need long-term and continued study in Chinese RA patients.

\section{Disclosure}

The authors report no conflicts of interest in this work.

\section{References}

1. Miossec P. Rheumatoid arthritis: still a chronic disease. Lancet. 2013;381(9870):884-886.

2. Li R, Sun J, Ren LM, et al. Epidemiology of eight common rheumatic diseases in China: a large-scale cross-sectional survey in Beijing. Rheumatology (Oxford). 2012;51(4):721-729.

3. Scott DL, Wolfe F, Huizinga TW. Rheumatoid arthritis. Lancet. 2010;376(9746):1094-1108. 
4. Wang XR, SuY, An Y, et al. 我国风湿关节炎患者应用肿瘤坏死因子 抑制剂现况调查. [Survey of tumor necrosis factor inhibitors application in patients with rheumatoid arthritis in China]. Beijing Da Xue Xue Bao. 2012;44(2):182-187. Chinese.

5. Hashizume M, Tan SL, Takano J, et al. Tocilizumab, a humanized anti-IL-6R antibody, as an emerging therapeutic option for rheumatoid arthritis: molecular and cellular mechanistic insights. Int Rev Immunol. Epub 2014 Aug 6.

6. Akira S, Taga T, Kishimoto T. Interleukin-6 in biology and medicine. Adv Immunol. 1993;54:1-78.

7. Yao X, Huang J, Zhong H, et al. Targeting interleukin-6 in inflammatory autoimmune diseases and cancers. Pharmacol Ther. 2014;141(2): 125-139.

8. Naugler WE, Karin M. The wolf in sheep's clothing: the role of interleukin-6 in immunity, inflammation and cancer. Trends Mol Med. 2008;14(3):109-119.

9. Nakahara H, Song J, Sugimoto M, et al. Anti-interleukin-6 receptor antibody therapy reduces vascular endothelial growth factor production in rheumatoid arthritis. Arthritis Rheum. 2003;48(6):1521-1529.

10. Tanaka T, Narazaki M, Kishimoto T. Therapeutic targeting of the interleukin-6 receptor. Annu Rev Pharmacol Toxicol. 2012;52:199-219.

11. Venkiteshwaran A. Tocilizumab. MAbs. 2009;1(5):432-438.

12. Sato K, Tsuchiya M, Saldanha J, et al. Reshaping a human antibody to inhibit the interleukin 6-dependent tumor cell growth. Cancer Res. 1993;53(4):851-856.

13. Mok CC, Tam LS, Chan TH, Lee GK, Li EK. Management of rheumatoid arthritis: consensus recommendations from the Hong Kong Society of Rheumatology. Clin Rheumatol. 2011;30(3):303-312.

14. Nishimoto N, Yoshizaki K, Maeda K, et al. Toxicity, pharmacokinetics, and dose-finding study of repetitive treatment with the humanized antiinterleukin 6 receptor antibody MRA in rheumatoid arthritis. Phase I/II clinical study. $J$ Rheumatol. 2003;30(7):1426-1435.

15. Oldfield V, Dhillon S, Plosker GL. Tocilizumab: a review of its use in the management of rheumatoid arthritis. Drugs. 2009;69(5):609-632.

16. Zhang X, Chen YC, Fettner S, et al. Pharmacokinetics and pharmacodynamics of tocilizumab after subcutaneous administration in patients with rheumatoid arthritis. Int J Clin Pharmacol Ther. 2013;51(8): 620-630.

17. Ohta S, Tsuru T, Terao K, et al. Mechanism-based approach using a biomarker response to evaluate tocilizumab subcutaneous injection in patients with rheumatoid arthritis with an inadequate response to synthetic DMARDs (MATSURI study). J Clin Pharmacol. 2014;54(1): 109-119.

18. Ogata A, Tanimura K, Sugimoto T, et al; Musashi Study Investigators. Phase III study of the efficacy and safety of subcutaneous versus intravenous tocilizumab monotherapy in patients with rheumatoid arthritis. Arthritis Care Res (Hoboken). 2014;66(3):344-354

19. ClinicalTrial.gov [homepage on the Internet]. US the National Library of Medicine (NLM); 2014. [updated August 26, 2014; cited August 29, 2014] Available from: http://www.clinicaltrials.gov/. Accessed August 29, 2014.

20. Fleischmann RM, Halland AM, Brzosko M, et al. Tocilizumab inhibits structural joint damage and improves physical function in patients with rheumatoid arthritis and inadequate responses to methotrexate: LITHE study 2-year results. J Rheumatol. 2013;40(2):113-126.

21. Genovese MC, McKay JD, Nasonov EL, et al. Interleukin-6 receptor inhibition with tocilizumab reduces disease activity in rheumatoid arthritis with inadequate response to disease-modifying antirheumatic drugs: the tocilizumab in combination with traditional disease-modifying antirheumatic drug therapy study. Arthritis Rheum. 2008;58(10): 2968-2980.

22. Jones G, Sebba A, Gu J, et al. Comparison of tocilizumab monotherapy versus methotrexate monotherapy in patients with moderate to severe rheumatoid arthritis: the AMBITION study. Ann Rheum Dis. 2010;69(1):88-96.

23. Smolen JS, Beaulieu A, Rubbert-Roth A, et al; OPTION Investigators Effect of interleukin-6 receptor inhibition with tocilizumab in patients with rheumatoid arthritis (OPTION study): a double-blind, placebocontrolled, randomised trial. Lancet. 2008;371(9617):987-997.
24. Singh JA, Beg S, Lopez-Olivo MA. Tocilizumab for rheumatoid arthritis. Cochrane Database Syst Rev. 2010;7:CD008331.

25. Nishimoto N, Hashimoto J, Miyasaka N, et al. Study of active controlled monotherapy used for rheumatoid arthritis, an IL-6 inhibitor (SAMURAI): evidence of clinical and radiographic benefit from an $\mathrm{x}$ ray reader-blinded randomised controlled trial of tocilizumab. Ann Rheum Dis. 2007;66(9):1162-1167.

26. Emery P, Sebba A, Huizinga TW. Biologic and oral disease-modifying antirheumatic drug monotherapy in rheumatoid arthritis. Ann Rheum Dis. 2013;72(12):1897-1904.

27. Gabay C, Emery P, van Vollenhoven R, et al; ADACTA Study Investigators. Tocilizumab monotherapy versus adalimumab monotherapy for treatment of rheumatoid arthritis (ADACTA): a randomised, double-blind, controlled phase 4 trial. Lancet. 2013;381(9877):1541-1550.

28. Smolen JS, Landewé R, Breedveld FC, et al. EULAR recommendations for the management of rheumatoid arthritis with synthetic and biological disease-modifying antirheumatic drugs: 2013 update. Ann Rheum Dis. 2014;73(3):492-509.

29. Zhang W, Shi Q, Wu DH, et al. Efficacy and safety of infliximab in patients with rheumatoid arthritis. Zhonghua Yi Xue Za Zhi. 2009;89(27):1876-1880.

30. Singh JA, Wells GA, Christensen R, et al. Adverse effects of biologics: a network meta-analysis and Cochrane overview. Cochrane Database Syst Rev. 2011;2:CD008794.

31. Maini RN, Taylor PC, Szechinski J, et al; CHARISMA Study Group. Double-blind randomized controlled clinical trial of the interleukin-6 receptor antagonist, tocilizumab, in European patients with rheumatoid arthritis who had an incomplete response to methotrexate. Arthritis Rheum. 2006;54(9):2817-2829.

32. Hennigan S, Kavanaugh A. Interleukin-6 inhibitors in the treatment of rheumatoid arthritis. Ther Clin Risk Manag. 2008;4(4):767-775.

33. Shi Q, Zhao Y, Bao CD, et al. The efficacy and safety of tocilizumab combined with disease-modifying anti-rheumatoid drugs in the treatment of active rheumatoid arthritis: a multi-center, randomized, double-blinded, placebo-controlled trial. Zhonghua Nei Ke Za Zhi. 2013;52(4):323-329.

34. Lopez-Olivo MA, Tayar JH, Martinez-Lopez JA, et al. Risk of malignancies in patients with rheumatoid arthritis treated with biologic therapy: a meta-analysis. JAMA. 2012;308(9):898-908.

35. Nishimoto N. Interleukin-6 in rheumatoid arthritis. Curr Opin Rheumatol. 2006;18(3):277-281.

36. Langley PC, Mu R, Wu M, Dong P, Tang B. The impact of rheumatoid arthritis on the burden of disease in urban China. J Med Econ. 2011; 14(6):709-719.

37. Strand V, Singh JA. Newer biological agents in rheumatoid arthritis: impact on health-related quality of life and productivity. Drugs. 2010; 70(2):121-145.

38. Fries JF, Spitz P, Kraines RG, Holman HR. Measurement of patient outcomes in arthritis. Arthritis Rheum. 1980;23(23):137-145.

39. Song Y, Zhu LA, Wang SL, Leng L, Bucala R, Lu LJ. Multi-dimensional health assessment questionnaire in china: reliability, validity and clinical value in patients with rheumatoid arthritis. PLoS One. 2014;9(5): e97952.

40. Smolen JS, Schoels MM, Nishimoto N, et al. Consensus statement on blocking the effects of interleukin- 6 and in particular by interleukin- 6 receptor inhibition in rheumatoid arthritis and other inflammatory conditions. Ann Rheum Dis. 2013;72(4):482-492.

41. Kremer JM, Blanco R, Brzosko M, et al. Tocilizumab inhibits structural joint damage in rheumatoid arthritis patients with inadequate responses to methotrexate: results from the double-blind treatment phase of a randomized placebo-controlled trial of tocilizumab safety and prevention of structural joint damage at one year. Arthritis Rheum. 2011;63(3):609-621.

42. Strand V, Burmester GR, Ogale S, Devenport J, John A, Emery P. Improvements in health-related quality of life after treatment with tocilizumab in patients with rheumatoid arthritis refractory to tumour necrosis factor inhibitors: results from the 24-week randomized controlled RADIATE study. Rheumatology (Oxford). 2012;51(10):1860-1869. 
43. Nishimoto N, Miyasaka N, Yamamoto K, et al. Study of active controlled tocilizumab monotherapy for rheumatoid arthritis patients with an inadequate response to methotrexate (SATORI): significant reduction in disease activity and serum vascular endothelial growth factor by IL-6 receptor inhibition therapy. Mod Rheumatol. 2009;19(1):12-19.
44. Dhillon S. Intravenous tocilizumab: a review of its use in adults with rheumatoid arthritis. BioDrugs. 2014;28(1):75-106.

\section{Publish your work in this journal}

The International Journal of General Medicine is an international, peer-reviewed open-access journal that focuses on general and internal medicine, pathogenesis, epidemiology, diagnosis, monitoring and treatment protocols. The journal is characterized by the rapid reporting of reviews, original research and clinical studies across all disease areas.
A key focus is the elucidation of disease processes and management protocols resulting in improved outcomes for the patient. The manuscript management system is completely online and includes a very quick and fair peer-review system. Visit http://www.dovepress.com/ testimonials.php to read real quotes from published authors.

Submit your manuscript here: http://www.dovepress.com/international-journal-of-general-medicine-journal 